\title{
Las diversas dimensiones del trabajo del docente y la necesidad de formación
}

Ma. de Lourdes Gallegos Gallegos

Victor Moreno Ramos

Carlos Torres Carrillo

\section{$\mathrm{P}$}

ara entender las implicaciones del trabajo que debe llevar a cabo un docente en educación superior que quiere realizar su labor de la mejor manera posible es necesario analizar la serie de elementos de las diferentes dimensiones implicadas de su labor académica, lo que ayudará a entender la complejidad de su tarea y las responsabilidades que esto conlleva.

El trabajo del docente se inserta en un contexto en el que podemos distinguir seis dimensiones. Las tres primeras influyen de manera general, como contexto que caracteriza este quehacer docente, y las tres últimas interactúan de forma específica en el momento en que el docente realiza su labor dentro del aula o en las actividades de asesoramiento o tutoría.

\section{Dimensión social}

La sociedad ha depositado en las instituciones educativas la responsabilidad de hacer operativas las propuestas para formar a sus ciudadanos. Las tendencias internacionales en materia educativa indican, en términos generales, que la educación para el siglo XxI deberá articularse en torno a cuatro grandes aspectos. Según Jaques Delors (1997) son aprender a conocer, aprender a hacer, aprender a vivir juntos y aprender a ser. Ante este reto, en México se trabaja en la actualización de estos aspectos en términos de transformación e innovación del sistema educativo en todos los niveles y, para este propósito, diversas instancias de diferentes ámbitos se han abocado a diseñar estrategias y programas al respecto.

Ahora bien, se habla de una serie de elementos deseables para llevar a cabo estas transformaciones, entre los que están una dirección central reforzada, la periferia de desarrollo extendida que se refiere al adecuado y necesario intercambio con grupos externos, la diversificación del financiamiento que permita la ampliación de las fuentes de obtención de recursos, el núcleo académico altamente estimulado, así como una cultura innovadora integrada que forme parte activa en todas las actividades que realiza una institución educativa; sin embargo, se reconoce que es en el aspecto de los grupos de académicos "donde es más probable que los cambios promovidos y las innovaciones fallen" (Clark, 2000: 35). Lo anterior habla de la necesidad de hacer trabajo permanente de promoción y desarrollo con los docentes para que tengan la posibilidad de asumir actitudes de apertura ante los cambios constantes. 
Cada sexenio se plasman algunos lineamientos en el Plan Nacional de Desarrollo y Plan Estatal de Desarrollo que, en materia educativa, se agrupan en los Programas de Desarrollo Educativo.

\section{Dimensión institucional}

Esta dimensión involucra una organización educativa en particular que vislumbra y propone una forma específica de lograr los objetivos sociales y que, como toda organización, tiene una serie de esquemas normativos para su operatividad que no puede desconocer aspectos económicos, políticos, legales, entre otros.

La misión enunciada por la Universidad Autónoma de Aguascalientes pretende:

formar a los estudiantes desde una perspectiva humanista que enfatiza el desarrollo equilibrado e integral de las dimensiones de su persona, lo cual les permita desempeñarse exitosamente como futuros profesionales y vivir la vida con plenitud y calidad; en generar, gestionar y aplicar conocimiento que responda a necesidades del contexto que derive en su permanente mejora; en difundir la cultura, la ciencia, la tecnología y el arte a la sociedad en su conjunto; así como vincularse de forma efectiva con la comunidad y realizar eficientemente las actividades de apoyo que faciliten y enriquezcan las funciones sustantivas. Todo ello con el propósito fundamental de contribuir al desarrollo sustentable de Aguascalientes y de México [sic] (UAA, 2013).

De igual manera, su lema, Se Lumen Proferre, nos da una idea de la perspectiva institucional. La organización académica y administrativa está conformada por el sistema departamental, que permite organizar a los grupos de maestros de una disciplina común en un solo lugar; éstos ofrecen servicios indistintamente a diferentes carreras y cursos, y utilizan los medios educativos -como aulas, laboratorios, etcétera- con el carácter de multiservicios.

Los departamentos, al ser de áreas más o menos afines, conforman los centros académicos. Actualmente la UAA cuenta con diez centros, en los que, para el período enero-junio 2013, se ofrecen sesenta opciones de licenciatura. La parte administrativa está formada por direcciones generales de apoyo en aspectos de esta índole.

El personal con el que cuenta la institución hasta ahora es de 1014 trabajadores, cifra que incluye al personal sindicalizado y de confianza. El personal académico reportado es de 2055 personas.

Entre los múltiples programas estratégicos que se promueven se encuentra la formación de los profesores en aspectos que fomentan el mejoramiento de sus actividades docentes y su desarrollo personal, esto permite un apoyo más cercano a los alumnos en su trayectoria como estudiantes y promueve la calidad de sus estudios y su formación integral.

En nuestra universidad, en el Plan de Desarrollo Institucional se plasman las líneas generales del curso que se va a seguir en el proyecto de la institución.

\section{Dimensión interpersonal}

Esta dimensión se refiere a la realización de actividades en grupo. Algunas de la actividades que realizan los académicos son los cursos de 
actualización, el trabajo en academias afines o bien el grupo de tutores académicos por centro y departamentos. Las actividades de revisión y diseño de planes de estudio, con la participación de varios departamentos académicos, también son una oportunidad de intercambio y enriquecimiento interpersonal para cada docente y para el grupo mismo, ya que la información compartida puede ayudar a crear un clima menos desafiante y amenazador para que los docentes aprendan de -y con- los colegas, donde cada uno pueda expresar lo que piensa identificando claramente las cuestiones personales de las laborales en las que puede no estar de acuerdo pero sí ser aceptado, en el que le sean reconocidos sus aciertos y reconozca sus errores y hasta sus carencias.

Este aspecto interpersonal va a permitir que el docente tenga disposición para desarrollar otras habilidades para la interacción. Ahora el docente se encuentra con actividades que le son asignadas y que no son las que tradicionalmente había estado realizando con los estudiantes, por lo que necesita incluirse de una manera mucho más interactiva en el proceso de desarrollo integral de los alumnos, tanto en la obtención de conocimientos como en habilidades, actitudes y valores, teniendo obviamente una mayor interacción de índole interpersonal.

Por ejemplo, desempeñarse como tutor académico -que es quien proporcionará los apoyos y le dará seguimiento cercano a la trayectoria del estudiante- requiere una serie de habilidades para la interacción y las relaciones interpersonales, independientemente de los contenidos que se van a tratar en este proceso.

\section{Dimensión disciplinar}

La dimensión disciplinar trata del conocimiento que tiene cada docente de su profesión, de la comprensión de su propio trabajo y de la relación de éste con otras disciplinas, así como de la constante indagación del desarrollo de las profesiones y de los avances científicos y tecnológicos que tienen lugar. Se debe hacer un esfuerzo constante para tener acceso a destacados profesionales o tener permanente intercambio con otras instancias que ayuden a este desarrollo, así como la asistencia a eventos especializados y de alta calidad para actualización; asimismo, hay que interesarse en aprender otro idioma para estar atento a la información y publicaciones que se generen en otros ámbitos.

Una estrategia para mejorar la calidad en la educación superior es que los docentes obtengan grados académicos que fomenten la generación y aplicación de conocimiento.

\section{Dimensión metodológico-didáctica}

Esta dimensión se relaciona con el conocimiento y uso de las estrategias específicas para la implementación de un determinado curso, así como de su planeación, ejecución y evaluación, tanto de los procesos de enseñanza como de los productos esperados de aprendizaje.

No se trata de si las estrategias deben centrarse en el docente o en el estudiante sino de la creación de una clase en la que todos los participantes son coaprendices. Desde la perspectiva humanista, como lo afirman Rogers y Freiberg, un aula puede incluir "una gran variedad de oportunidades para que el profesor y los alumnos aprendan. Debería haber un continuum de opciones de enseñanza y aprendizaje que fuera parte del repertorio de cada persona" (1996: 222). 
El docente debe cuestionarse qué tanto una determinada temática puede apoyar la formación de un profesional y cómo hacer que los objetivos que se proponen sean compatibles con los intereses de los estudiantes. Este docente debe conocer una serie de técnicas y estrategias metodológicas e identificar los recursos de los propios estudiantes, y éstos deberán ser utilizados por el grupo para las diversas experiencias de aprendizaje. También, debe reconocer los recursos que ofrecen la comunidad y la institución, así como todas las instancias que le pueden proporcionar información y las diversas propuestas innovadoras a las que le permite acceder el desarrollo tecnológico.

\section{Dimensión personal}

Esta dimensión tiene que ver con las posibilidades y capacidades del docente para convivir con otras personas (qué tanto le amenaza al docente el contacto humano) y por consiguiente con su capacidad para valorar esta posibilidad de enriquecimiento personal. Esta dimensión personal del docente se relaciona con que cada profesor reflexione sobre cuáles son sus intereses y sus motivaciones al realizar su trabajo, lo que se verá reflejado en cómo realiza sus actividades.

Si un docente cuenta con un adecuado desarrollo del aspecto personal manifestará un real interés por las personas y su mejoramiento, tendrá una visión positiva del futuro y por objetivo de trabajo la promoción de los estudiantes y claridad en su papel como agente de cambio. Es en esta dimensión en donde se hará notorio si un docente sabe resolver sus propias situaciones personales y profesionales, si cuenta con una valoración adecuada de sí mismo, confianza personal y flexibilidad para las nuevas ideas. Un docente con un adecuado desarrollo de esta dimensión asumirá por convicción la responsabilidad de su compromiso y esto se reflejará en su actuar.

Ahora bien, al momento de realizar sus actividades docentes, los tres elementos que influyen de forma inmediata en el trabajo del aula son la dimensión disciplinar, que hace alusión al conocimiento de los contenidos o el curso con el que está participando en la formación de profesionistas; la dimensión metodológico-didáctica, que hace referencia a las estrategias a las que recurre el docente para hacer llegar el aprendizaje a los estudiantes, y la dimensión personal, que permite que este docente sea flexible o rígido en la creación de ambientes del trabajo con los estudiantes, si permite la participación y la interacción entre los estudiantes y si favorece en realidad su desarrollo.

La importancia de conocer estas diversas dimensiones en las que se enmarca el trabajo en el aula, en apariencia sencillo, permite tener una comprensión del impacto de las tareas que cada docente realiza con su quehacer diario y que un alto porcentaje de docentes no alcanza a captar del todo. Cuando el profesor logra entender esta importancia se da cuenta de la gran necesidad de mejorar en su formación en todas sus dimensiones para asumir con responsabilidad este reto. 


\section{Fuentes de consulta}

Blanco, R. (1982). Docencia universitaria y desarrollo humano. México: Alhambra.

Clark, B. (2000). Creando universidades innovadoras: Estrategias organizacionales para la transformación. México: Universidad Nacional Autónoma de México.

Delors, J. (Coord.). (1997). La educación encierra un tesoro. México: Correo de la UNESCO.

Gallegos, M., Moreno, V. y Torres, C. (2012). Bases del quehacer docente en la formación humanista universitaria. En Docere, 6, mayo 2012.

Gallegos, M., y Torres, C. (2012). Implicaciones personales en la implementación del Modelo Educativo Institucional. En Memorias del Segundo Coloquio Mexicano de Investigación en Desarrollo Humano. De la investigación al ejercicio profesional. México: IETEC-Arana. Rogers, C.R. y Freiberg, H. J. (1996). Libertad y creatividad en la educación. Barcelona: Paidós.

UAA. (2013). Folleto informativo para profesores. México: UAA.

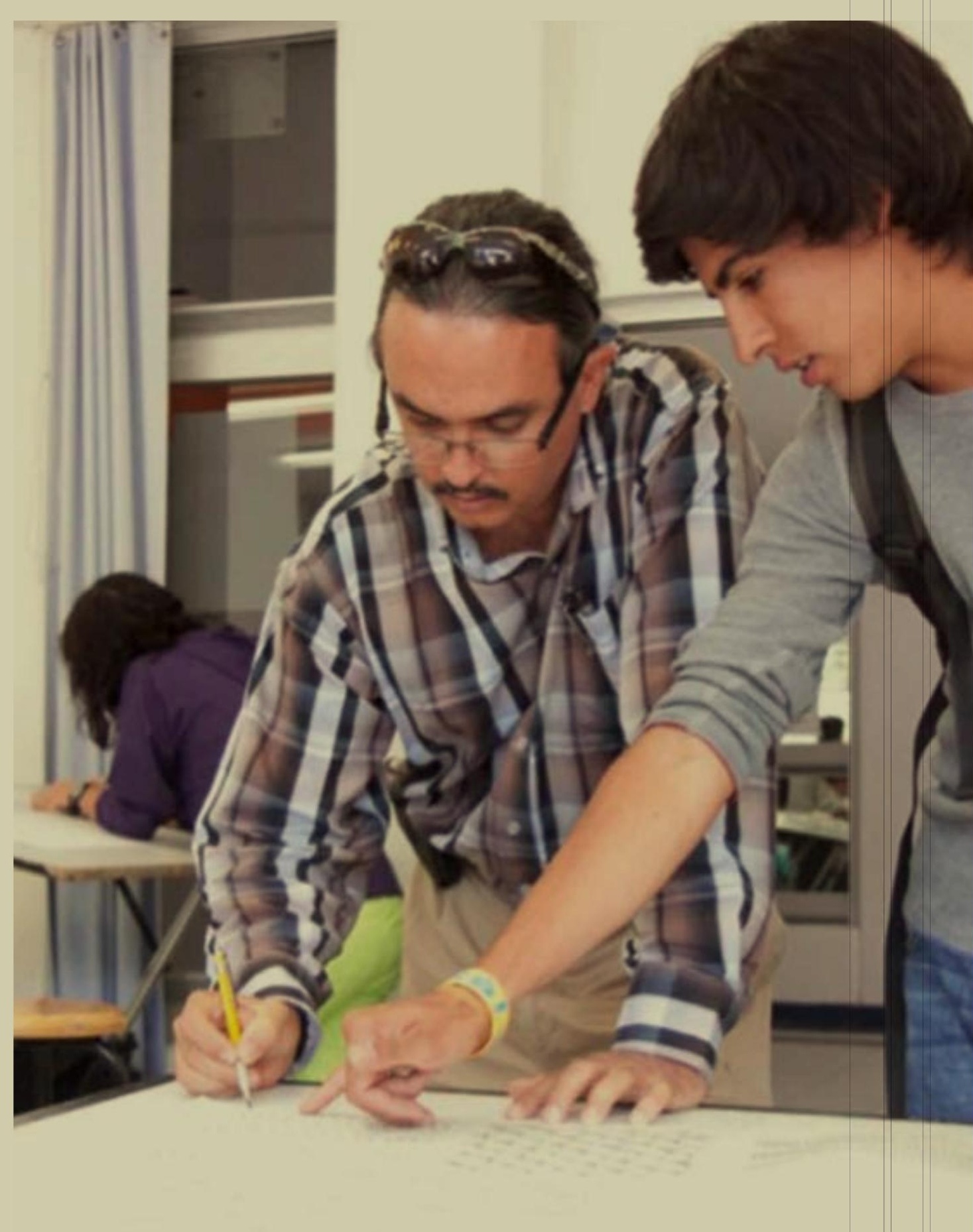

